\title{
O Pibid Diversidade na UFGD: conquistas e desafios
}

\author{
LADEIA, Elâine da Silva ${ }^{1}$ \\ SANGALLI, Andréia ${ }^{2}$
}

\section{RESUMO}

O presente texto traz reflexões sobre o Programa Institucional de Bolsa de Iniciação à Docência - PIBID Diversidade, desenvolvido pelo curso de Licenciatura Intercultural Indígena - Teko Arandu, na Universidade Federal da Grande Dourados (UFGD). O PIBID D iniciou suas atividades em 2011. A metodologia para construção do texto pautou-se em discutir o contexto do pibid diversidade na UFGD e na formação de professores; pibid diversidade como política pública de educação; quem são e onde estão os sujeitos indígenas? Ações/atividades desenvolvidas pelos subprojetos; resultados e os impactos da edição atual e anterior; as conquistas e os desafios do Pibid Diversidade. Dentre os resultados alcançados destacam-se: Maior interação entre os docentes do curso de Licenciatura Indígena e entre os docentes e as escolas e comunidades indígenas, permitindo um conhecimento mais aproximado da realidade vivida nessas escolas (aspectos estruturais, recursos didáticos e dificuldades enfrentadas pelos professores que atuam nessas escolas); Contribuir no desenvolvimento de conceitos teóricos através de oficinas práticas com os bolsistas e estudantes das escolas indígenas possibilitando a discussão de conhecimentos tradicionais e ocidentais sobre esses conceitos; Discutir conteúdos nas diversas áreas de conhecimento e a sua (re) elaboração no âmbito do ensino escolar indígena, a partir da prática pedagógica dos professores, da abordagem dos livros didáticos disponíveis e da contextualização do ensino associado aos conhecimentos tradicionais; Desenvolver habilidades para a escolha de metodologias, procedimentos didáticos e paradigmas científicos/tradicionais englobando processos que melhorem seu conhecimento profissional.

PIBID. Diversidade. Universidade Federal de Grande Dourados.

\section{The Pibid Diversidade in the UFGD: achievements and challenges}

\begin{abstract}
The present text reflects on the Institutional Scholarship Initiative Program for Diversity - PIBID Diversidade, carried out by the Indigenous Intercultural Licentiate course - Teko Arandu, at the Grande Dourados Federal University (UFGD). The PIBID started its activities in 2011. The methodology for the text construction was intended to discuss the Pibid Diversidade organizational context at UFGD and on the teachers training; Pibid as public education policy;

\footnotetext{
${ }^{1}$ Docente da Faculdade Intercultural Indígena/TEKO ARANDU1/UFGD. Mestre em Agricultura Tropical/UFMT. Doutoranda em Geografia/PPGG/UFGD.

${ }^{2}$ Docente da Faculdade Intercultural Indígena/LEDUC2/UFGD. Doutora em Agronomia Produção Vegetal/PPGA/UFGD.
} 
who are and where are the indigenous individuals? Actions/activities promoted by subprojects; Results and the impacts of the current and previous edition; The achievements and challenges of the Pibid Diversity. Among the results achieved, stands out: Greater interaction between Indigenous Licentiate course teachers and among teachers, schools and the indigenous communities, allowing a closer knowledge about the reality lived in these schools (structural aspects, didactic resources and difficulties faced by the teachers who work in these schools); To contribute in the theoretical concepts development through practical workshops with the scholarship holders and the indigenous schools students enabling the discussion of traditional and Western knowledge about these concepts; To discuss content in the various areas of knowledge and their (re)elaboration in the scope of indigenous school education, based on the teachers pedagogical practice, on approach to available textbooks and contextualization of teaching process associated with traditional knowledge; To Develop skills to choose methodologies, didactic procedures and scientific / traditional paradigms encompassing processes that improve their professional knowledge.

PIBID. Diversity. Grande Dourados Federal University.

\section{O contexto do Pibid diversidade na UFGD e na formação de professores}

As discussões iniciais acerca da implantação do PIBID-Diversidade na UFGD iniciaram em 2010, e em 2011 houve a concretização da implantação desse programa. Desde o princípio, ele esteve voltado para atender a demanda das populações vulneráveis que também são as minorias nas Instituições de Ensino Superior, nas quais incluem-se os povos indígenas e os povos do campo, representados na UFGD nos cursos de Licenciatura Intercultural Indígena e Licenciatura em Educação do Campo que funcionam na Faculdade Intercultural Indígena - FAIND/UFGD.

Sobre a implantação do programa, a UFGD foi contemplada então, naquela que seria a primeira edição, ou seja, o primeiro edital para PIBID Diversidade, Edital Conjunto n²/2010/Capes/Secad-MEC - Pibid Diversidade e no segundo Edital CAPES № 66/2013 o Programa alcançou uma quantidade ampla de bolsistas em todo o país, atingindo um de seus principais objetivos, o de promover a aproximação entre a universidade e as escolas de educação básica, dentre outros.

O PIBID Diversidade FAIND/UFGD foi constituído por acadêmicos indígenas, haja vista que o curso de Licenciatura Indígena é um curso específico para os povos Guarani e Kaiowá do Cone sul de MS. Esses acadêmicos em sua maioria são professores leigos que atuam nas escolas das aldeias, e frequentam essa licenciatura para obterem formação específica e 
conquistarem o diploma de graduação a fim de garantirem o direito de lecionarem em suas escolas nas séries da Educação Básica- Ensino Fundamental e Ensino Médio, como está previsto na legislação brasileira referente à Formação de Professores

O curso também atende à demanda do etnoterritório educacional Cone Sul de MS, onde a UFGD é parceira na formação de professores indígenas, garantindo o que rege a Constituição Federal de 1988, de que a educação escolar indígena deve ser específica, bilíngue e diferenciada, e só poderemos alcançar esse propósito se fora garantido a esses povos, uma formação diferenciada, que respeite seus saberes e suas culturas.

O curso de Licenciatura Intercultural Indígena está estruturado sob um tripé que envolve: o Teko - a cultura; o Tekohá - o local onde se pratica a cultura; e o Nhẽe - a língua.

O PIBID diversidade foi então pensado e proposto respeitando esses eixos, sendo desenvolvidas ações de fortalecimento do tripé Teko, Tekohá e Nhẽe.

\section{PIBID - Uma Política Pública de Educação}

O Programa de Bolsas de Iniciação à Docência IBID pode ser considerado como um Programa de Política Pública na formação de professores para a Educação Básica. Essa afirmação foi consensuada por diversos pesquisadores na área de gestão escolar e formação de professores.

Os elementos em destaque para 0 estabelecimento dessa transformação de Programa à Política Pública tendem a se concretizar a partir das ações realizadas por sua natureza e abrangência, que podem ser caracterizadas como uma política pública de formação de professores. Este movimento tende a ser reafirmado pela ação dos seus aprendentes (coordenadores de área, supervisores e ids- bolsistas de iniciação à docência) por meio de suas aprendizagens (SILVA \& NUNES, 2016).

O PIBID foi um dos três programas identificados como política de parceria universidade e escola, quais seriam os outros programas?? Apontado como uma iniciativa muito positiva de articulação entre a teoria e a prática, promovendo a práxis pedagógica (FCC, 2012).

O PIBID alcançou uma posição de referência no campo das políticas públicas educacionais, a partir de suas implicações para a concepção de formação docente (ASSIS, 2016). Uma das grandes conquistas desse programa foi sua contribuição para a valorização da profissão de professor, bem como a mobilização promovida entre a universidade e as escolas, além é 
claro, de constituir-se em rara política de atenção à formação inicial dos professores para a educação básica (FCC, 2012).

A dicotomia entre teoria e prática é problema superado com a aproximação entre IES e escolas, ligando o campo da profissão ao da formação, com valorização da escola como lócus de produção de conhecimento e formação docente. Nesse modelo de formação, valoriza-se 0 princípio da investigação na ação e o sujeito como protagonista da própria formação (ASSIS, 2016).

O PIBID Diversidade FAIND/UFGD como Política Pública possibilitou que os indígenas assumissem a Educação Escolar indígena pois na maioria das escolas indígenas predominam professores e gestores não indígenas; o programa atua de maneira diferenciada em suas ações em relação aos demais cursos participantes, e buscam na Formação específica e intercultural o reconhecimento e a valorização da diversidade étnica, cultural e linguística no Estado de MS.

Quanto a aproximação entre as escolas e seus formadores, podemos concordar com Tardif (2002), quando ele aponta que o distanciamento entre os espaços de formação e de trabalho deve constituir fator de grande preocupação entre os responsáveis pela formação dos professores, pois a escola é o espaço estruturante da atividade docente.

Tardif (2002), destaca também que os saberes profissionais dos professores são situados, ou seja, são construídos e ganham sentido em função dos contextos de trabalho nos quais são exercidos, e questiona 0 modelo universitário de formação profissional ao discutir o papel das faculdades de educação na formação dos futuros professores, observando que os cursos são geralmente idealizados segundo um modelo apenas "aplicacionista", em que:

[...] os alunos passam certo número de anos a assistir a aulas baseadas em disciplinas e constituídas de conhecimentos proposicionais. Em seguida, ou durante essas aulas, eles vão estagiar para "aplicarem" esses conhecimentos. [...] Um dos problemas desse modelo, segundo o autor, é a organização curricular baseada em uma lógica disciplinar, focada no conhecimento teórico e distanciada do estudo da realidade das escolas e professores, "resultando na dissociação entre o conhecer e o fazer na formação docente" (TARDIF, 2002).

\section{Quem são e onde estão os Sujeitos Indígenas?}


O campo de atuação do PIBID diversidade foi o CONE SUL DE MS, constituído por 15 municípios, nos quais foram desenvolvidas atividades em 21 aldeias indígenas, abrangendo mais de 24 escolas indígenas (Tabela 1).

Inicialmente foram 180 bolsistas de iniciação científica, que permaneceram até o ano de 2015 quando houve uma auditoria e então o a CAPES* constatou que em muitas instituições estavam ocorrendo duplicidade de bolsas, tendo em vista os programas desenvolvidos nas universidades e demais instituições de ensino.

Tabela 1. Escolas Parceiras do PIBID Diversidade UFGD

\begin{tabular}{|c|c|c|c|c|}
\hline Nome da escola & \multicolumn{2}{|c|}{ IDEB } & Número & Nível \\
\hline $\begin{array}{l}\text { Escola Municipal Indígena(EMI) Mita Rory - } \\
\text { Amambai - Aldeia Amambai }\end{array}$ & $\begin{array}{l}(1) \\
3,7\end{array}$ & $\begin{array}{l}(2) \\
4,3\end{array}$ & $\begin{array}{c}(3) \\
529\end{array}$ & $\begin{array}{l}\text { Alunos do Ensino } \\
\text { Fundamental e Médio }\end{array}$ \\
\hline $\begin{array}{l}\text { EMI Mbo Erenda Tupâ I Nandeva - Amambai - } \\
\text { Aldeia Limão Verde }\end{array}$ & $\begin{array}{l}* \star \star \\
5,7\end{array}$ & $\begin{array}{l}* * * \\
4,3\end{array}$ & 330 & $\begin{array}{l}\text { Alunos do Ensino } \\
\text { Fundamental e Médio }\end{array}$ \\
\hline $\begin{array}{l}\text { EMI Mbo Eroy Tupã I Arandu Renoi - Antonio } \\
\text { João - Aldeia Campestre }\end{array}$ & 2,9 & 4,1 & 287 & $\begin{array}{l}\text { Alunos do Ensino } \\
\text { Fundamental }\end{array}$ \\
\hline EMI Acampamento Guaiviry - Aral Moreira & 4,7 & $\begin{array}{ll}* * * \\
3,9\end{array}$ & * & $\begin{array}{l}\text { Alunos do Ensino } \\
\text { Fundamental }\end{array}$ \\
\hline EMI Piracua - Bela Vista - Aldeia Pirakuá & 4,6 & 4,0 & 95 & $\begin{array}{l}\text { Alunos do Ensino } \\
\text { Fundamental e Médio }\end{array}$ \\
\hline EMI Nandejara Polo - Caarapó - Aldeia Tey’ikuê & 5,0 & $\begin{array}{l}* \star * \\
3,7\end{array}$ & 1352 & $\begin{array}{l}\text { Alunos do Ensino } \\
\text { Fundamental e Médio }\end{array}$ \\
\hline $\begin{array}{l}\text { EMI Nande Reko Arandu - Coronel Sapucaia - } \\
\text { Aldeia Taquapery }\end{array}$ & 4,7 & 3,8 & 752 & $\begin{array}{l}\text { Alunos do Ensino } \\
\text { Fundamental e Médio }\end{array}$ \\
\hline EMI Agustinho - Dourados - Aldeia Bororó & -- & -- & 537 & $\begin{array}{l}\text { Alunos do Ensino } \\
\text { Fundamental }\end{array}$ \\
\hline EMI Ramão Martins - Dourados - Aldeia Bororó & -- & -- & 414 & $\begin{array}{l}\text { Alunos do Ensino } \\
\text { Fundamental }\end{array}$ \\
\hline EMI Araporã - Dourados - Aldeia Jaguapiru & -- & -- & 614 & $\begin{array}{l}\text { Alunos do Ensino } \\
\text { Fundamental e Médio }\end{array}$ \\
\hline $\begin{array}{l}\text { EMI Tengatuí Marangatu - Dourados - Aldeia } \\
\text { Jaguapiru }\end{array}$ & 2,9 & 2,9 & 881 & $\begin{array}{l}\text { Alunos do Ensino } \\
\text { Fundamental e Médio }\end{array}$ \\
\hline $\begin{array}{l}\text { EMI PAI Chiquito Chiquito Pedro - Dourados - } \\
\text { Aldeia Panambizinho }\end{array}$ & -- & -- & 71 & $\begin{array}{l}\text { Alunos do Ensino } \\
\text { Fundamental e Médio }\end{array}$ \\
\hline $\begin{array}{l}\text { Escola Estadual Indígena Guateka Marçal de } \\
\text { Souza - Dourados - Aldeia Jaguapiru }\end{array}$ & -- & -- & +-200 & Alunos do Ensino Médio \\
\hline $\begin{array}{l}\text { EMI Joãozinho Carapé Fernando - Douradina - } \\
\text { Aldeia Panambi }\end{array}$ & 2,9 & 3,5 & 195 & $\begin{array}{l}\text { Alunos do Ensino } \\
\text { Fundamental }\end{array}$ \\
\hline $\begin{array}{l}\text { EMI Mbo Erro T O Rendy - Eldorado - Aldeia } \\
\text { Cerrito }\end{array}$ & 5,0 & 4,2 & 140 & $\begin{array}{l}\text { Alunos do Ensino } \\
\text { Fundamental e Médio }\end{array}$ \\
\hline
\end{tabular}




\begin{tabular}{|c|c|c|c|c|}
\hline EIEF Guarani Polo - Japorã - Aldeia Porto Lindo & 4,5 & 4,1 & 862 & $\begin{array}{l}\text { Alunos do Ensino } \\
\text { Fundamental e Médio }\end{array}$ \\
\hline EMI Acampamento Gauimbé - Laguna Carapã & 3,8 & 3,6 & * & $\begin{array}{l}\text { Alunos do Ensino } \\
\text { Fundamental e Médio }\end{array}$ \\
\hline EMI Mbo Erro Aranduí - Juti - Aldeia Taquara & 3,9 & 3,3 & 36 & $\begin{array}{l}\text { Alunos do Ensino } \\
\text { Fundamental }\end{array}$ \\
\hline EMI Acampamento Ypoí - Paranhos & 4,7 & $\begin{array}{ll}* \star * * \\
3,1\end{array}$ & * & $\begin{array}{l}\text { Alunos do Ensino } \\
\text { Fundamental }\end{array}$ \\
\hline EMI - Paranhos - Aldeia Paraguasu & 4,7 & 3,1 & * & $\begin{array}{l}\text { Alunos do Ensino } \\
\text { Fundamental }\end{array}$ \\
\hline $\begin{array}{l}\text { EMI Professor Adriano Pires - Paranhos - Aldeia } \\
\text { Potrero Guasu }\end{array}$ & $\begin{array}{l}* * * \\
4,7\end{array}$ & $\begin{array}{l}* * * \\
3,1\end{array}$ & 557 & $\begin{array}{l}\text { Alunos do Ensino } \\
\text { Fundamental }\end{array}$ \\
\hline EMI Pancho Romero - Paranhos -Aldeia Pirajuí & $\begin{array}{l}* * * \\
4,7\end{array}$ & $\begin{array}{l}* * * \\
3,1\end{array}$ & 413 & $\begin{array}{l}\text { Alunos do Ensino } \\
\text { Fundamental }\end{array}$ \\
\hline $\begin{array}{l}\text { EMI Jataivary - Ponta Porã - Acampamento } \\
\text { Lima Campo }\end{array}$ & $\begin{array}{ll}* * * \\
4,8\end{array}$ & $\begin{array}{ll}* * * \\
3,8\end{array}$ & 38 & $\begin{array}{l}\text { Alunos do Ensino } \\
\text { Fundamental }\end{array}$ \\
\hline $\begin{array}{l}\text { Acampamento Indígena Laranjeira Nhanderu - } \\
\text { Rio Brilhante }\end{array}$ & $\begin{array}{l}* * * \\
5,2\end{array}$ & $\begin{array}{l}* * * \\
3,7\end{array}$ & $*$ & $\begin{array}{l}\text { Alunos do Ensino } \\
\text { Fundamental e Médio }\end{array}$ \\
\hline $\begin{array}{l}\text { EMI Ubaldo Arandu KWE MI - Tacuru - Aldeias } \\
\text { Jaguapiré e Sassoró }\end{array}$ & $\begin{array}{l}* * * \\
4,8\end{array}$ & $\begin{array}{l}* * * \\
3,6\end{array}$ & 943 & $\begin{array}{l}\text { Alunos do Ensino } \\
\text { Fundamental e Médio }\end{array}$ \\
\hline
\end{tabular}

1 IDEB Média do município, do $4^{\circ}$ ao 5ํano, de acordo com CENSO 2013 INEP/MEC

2 IDEB médio do município, do $8^{\circ}$ ao $9^{\circ}$ ano, de acordo com CENSO 2013 INEP/MEC

3 Dados obtidos de acordo com CENSO 2013 INEP/MEC

* Escolas que não foram encontrados registros no CENSO 2013 INEP/MEC

*** média do município.

-- não foram encontrados registros.

Dados INEP/MEC acessado em 15/02/2015.

Constatada essa duplicidade, as bolsas foram suspensas e deu-se então a cobrança quanto à devolução das mesmas, contudo, ocorreu um prejuízo no andamento das atividades em desenvolvimento, culminado pela falta de repasse dos recursos de custeio do programa dados os cortes realizados pelo governo federal, especialmente no setor da educação, o que atingiu em grande medida o PIBID.

Com essa feita, a CAPES, reduziu então o número de bolsistas do PIBID diversidade FAIND/UFGD, e então resultaram 100 bolsistas. As vagas suspensas e canceladas pela duplicidade de bolsas não puderam ser substituídas no todo.

Nossos bolsistas, como já anunciado, sempre foram os Professores Indígenas Guarani/Kaiowá, atuantes nas escolas indígenas de suas aldeias, os quais vivem em condições e situações de territorialização diferenciadas: aldeias, acampamentos, reservas, áreas de retomada e também Terras indígenas já homologadas. 
$\mathrm{Na}$ Figura 01, é possível identificar a distribuição dos territórios indígenas no Estado de Mato Grosso do Sul - MS, a partir de 14 municípios. É importante ressaltar que esses povos estão distribuídos em duas etnias, os Guarani e os Kaiowás, dentro do território etnoeducacional Cone Sul (TEE CONE SUL) - localizado no sul de MS, nesse etnoterritório pressupõe-se que essas duas etnias possam ter garantidas o controle e gestão autônoma de suas terras bem como de suas escolas.

Figura 01. Mapa de localização das terras indígenas em MS

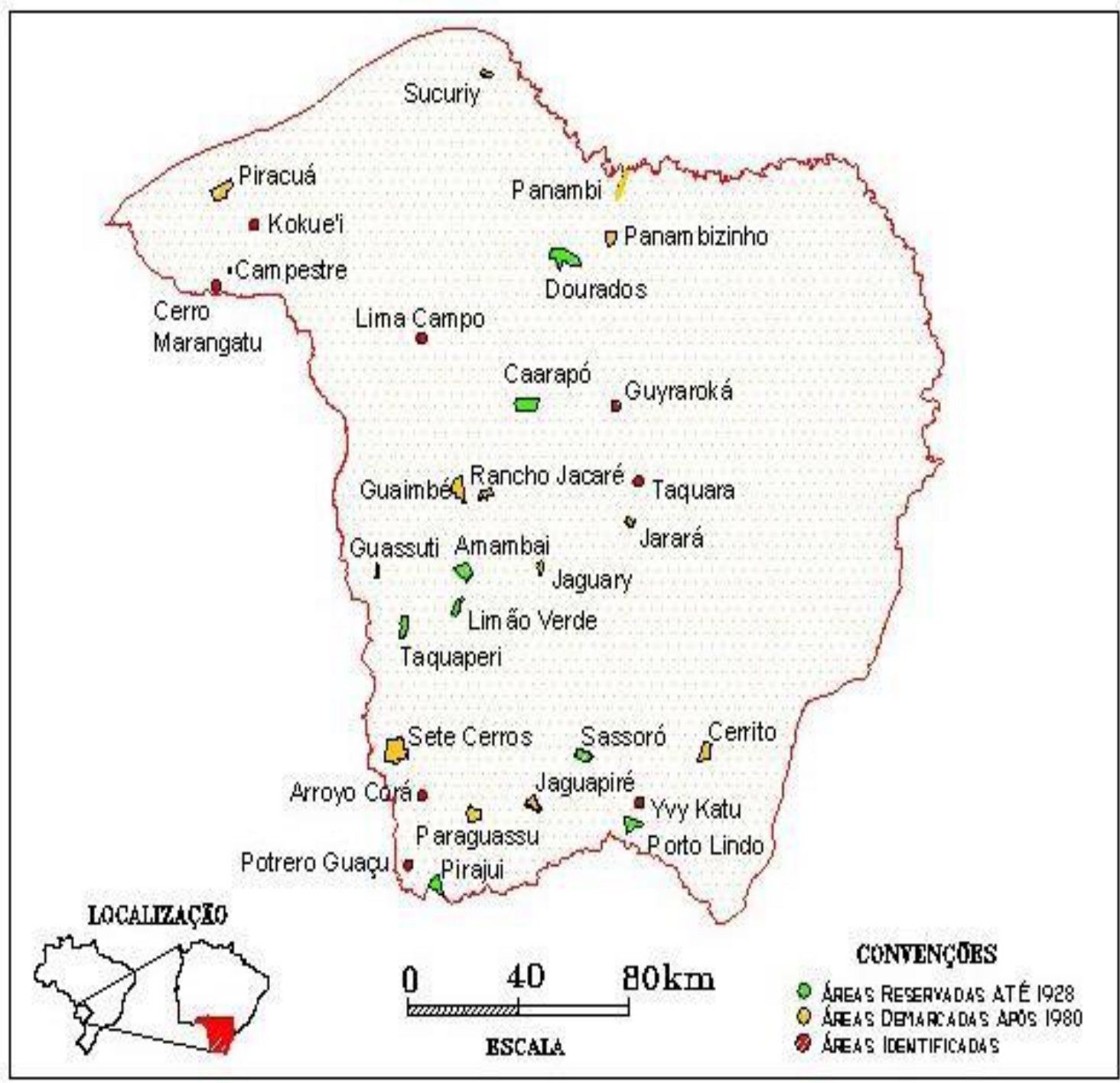

Fonte: VINHA et al | (2015)

Quanto à educação escolar indígena, o contexto no Cone Sul do MS é perpassado pela especificidade do Território Etnoeducacional Cone Sul, composto pelos povos autodenominados Kaiowá e Guarani de 26 municípios, embora a oferta regular de ensino na modalidade de educação escolar indígena, em escolas indígenas, ocorra em apenas 16 destes municípios. 
A maioria dessas escolas é mantida e gerida pelos municípios. Mas, segundo dados levantados pelo próprio MEC, mediante contratação de consultoria, em outros 02 municípios há atendimento escolar para alunos indígenas em escolas não indígenas municipais, urbanas ou rurais; em 08 municípios não há menção à educação escolar indígena, nem mesmo como atendimento a alunos indígenas, muito embora para alguns desses municípios seja indicada a existência de acampamentos indígenas.

Dados de 2011, obtidos junto à SECADI, indicam a existência de 31 escolas indígenas, com 13.419 estudantes e 486 professores indígenas no Cone Sul do MS (Projeto PIBID D 2013-2017).

Considerando-se a condição particular de vida de cada uma das mais de 200 sociedades indígenas que vivem em território brasileiro, surgem questões quanto à possibilidade e à necessidade de que as políticas públicas se adaptem a essa diversidade, à forma pela qual os povos indígenas estão organizados, o Ministério da Educação propôs nova modalidade de organização político-administrativa e territorial de assistência aos índios: os "Territórios Etnoeducacionais" (DE PAULA e VIANNA, 2011; p.22 e 23).

O 'Território Etnoeducacional Cone Sul' está composto por escolas indígenas localizadas em todos os municípios que foram pactuados. São 28 escolas-polo indígenas (municipais e estaduais), sendo quatro escolas vinculadas a missões evangélicas e várias extensões de escolas indígenas e/ou urbanas. Os municípios que pactuaram são os seguintes: Dourados, Maracaju, Douradina, Rio Brilhante, Bela Vista, Antônio João, Caarapó, Juti, Aral Moreira, Laguna Carapã, Amambai, Ponta Porã, Coronel Sapucaia, Tacuru, Eldorado, Paranhos e Sete Quedas. Em suas jurisdições municipais há reservas indígenas, aldeias retomadas e, ainda, acampamentos indígenas (VINHA et al, 2015, p. 04).

A maioria das escolas do TEE Cone Sul está localizada em territórios indígenas e cadastrada como 'indígena', cujos Projetos Políticos Pedagógicos (PPP) estão concretizados ou em construção pelos coletivos indígenas. Algumas ainda estão na condição de 'extensão' de alguma escola rural ou urbana, significando que seu PPP não assegura condições para o bilinguismo, para a valorização da cultura, para as negociações próprias da interculturalidade, dentre outros fatores. Há também aquelas que, apesar da designação de 'escola indígena', apresentam sérias dificuldades para operacionalizar as conquistas étnicas, devido às inúmeras situações e, dentre elas, a condição de diálogo e aceitação para com as diferenças, visto a legislação já assegurar tais conquistas (VINHA et al, 2015, p. 05). 


\section{Atividades/ações desenvolvidas pelos subprojetos}

As atividades desenvolvidas estimularam aos acadêmicos indígenas valorizar seus saberes tradicionais através do desenvolvimento de práticas pedagógicas nas escolas e ao mesmo tempo promover a aproximação com os mestres tradicionais que tornaram efetivos os diálogos entre os saberes indígenas e escolares.

No campo teórico, a discussão durante as apresentação e partilha destas experiências em Congressos e outros eventos possibilitou a reflexão do papel do educador indígena neste contexto, visando a construção de um currículo intercultural e ainda a reafirmação dos desafios para a construção de metodologias que permitam uma práxis pedagógica específica.

Em todo o período de desenvolvimento das atividades do PIBID foi também proporcionada a participação da comunidade local, representada pelos pais dos estudantes, lideranças, jovens, agentes de saúde, mestres tradicionais e lideres familiares, visto que em muitas das escolas indígenas essa comunidade externa já participa no processo de construção do Projeto Pedagógico Curricular e da proposta de currículo que caracterize a educação escolar indígena

Nas reflexões podemos ainda observar que o espaço da escola na aldeia possibilita o encontro de várias culturas e realidades particulares que compõem a própria aldeia, além das culturas da sociedade ocidentalizada, 0 que permite uma realidade de fronteira das diversas culturas no mesmo espaço. Essa situação resulta na pluralidade da composição da identidade Guarani Kaiowá como forma de estratégias de resistências diante das ondas de realidades globalizantes.

Nesse sentido o papel do educador indígena vai para além das atividades em sala de aula ou na escola indígena; ele deve buscar o constate diálogo entre a diversidade de situações existentes na aldeia e negociações estratégicas que ocorrem com as culturas de tendências homogeneizantes, e para isso deve estar em constante observação às questões socioeconômicas, políticas e ambientais que permeiam o entorno da escola.

\subsection{Das Atividades Desenvolvidas}

Durante o primeiro ano de desenvolvimento do Programa, as atividades os bolsistas juntamente com as equipes escolares de sua comunidade despertaram para a necessidade de aprofundamento nos conhecimentos necessários para aprimorar os conteúdos e as metodologias aplicadas na educação escolar indígena de suas comunidades. Desse modo, as discussões promovidas nos grupos de trabalho do PIBID D, contribuíram para a aproximação dos bolsistas e demais docentes atuantes nas escolas em questão, corroborando para um planejamento das atividades de forma coletiva 
e diferenciada, visando sempre a preservação e respeito aos conhecimentos tradicionais existentes em cada unidade escolar das aldeias indígenas em que atuaram os acadêmicos bolsistas da Licenciatura Intercultural Indígena.

Essas ações e discussões também proporcionaram um interesse na formação profissional dos docentes das unidades escolares, visando a entrada em cursos de pós-graduação Stritu e Latu Sensu, oferecidas nas IES de MS. A FAIND /UFGD iniciou uma especialização em 2014, e nesse curso ingressaram cerca de 20 egressos da Licenciatura Intercultural Indígena Teko Arandu, oriundos das escolas e comunidades indígenas de atuação do PIBID Diversidade/FAIND/UFGD. Também nesse primeiro ano houve um compartilhamento das atividades do projeto SABERES INDIGENAS NA ESCOLA - MEC/SECADI, o qual foi muito satisfatório, pois as contribuições desse projeto ressaltaram a necessidade de manter e preservar os saberes tradicionais e tomar conhecimento dos saberes ocidentais para o sucesso da educação escolar indígena.

As atividades desenvolvidas durante a primeira etapa do PIBID proporcionaram um envolvimento dos acadêmicos da Licenciatura Intercultural Indígena junto as demais licenciaturas da IES, pois a realização das atividades depende da interação entre os professores da rede de ensino público das escolas indígenas e não indígenas dos Municípios de MS, nas quais também se encontram acadêmicos de outras licenciaturas desenvolvendo atividades próximas as do projeto do PIBID D/FAIND/UFGD. Essa interação autentica não só a formação profissional como também promove a valorização dos saberes acadêmicos e tradicionais para os bolsistas em questão.

A constatação desse envolvimento foi observada na realização do I Congresso Internacional de Estudos Interculturais e I Seminário de Avaliação do PIBID Diversidade, no qual muitos acadêmicos e professores da UFGD e de outras IES participaram. Durante as apresentações de trabalhos e palestras houve a participação e envolvimento dos acadêmicos indígenas e não indígenas de diversas licenciaturas tornando esse momento de extrema importância ao PIBID D, pela riqueza na troca de saberes, e principalmente porque através dessas ações foi possível desmistificar um pouco a questão do preconceito e do aprendizado em relação às populações indígenas.

O processo de realização de oficinas e discussões dentro e fora das IES com a participação de acadêmicos de outras licenciaturas tem promovido uma aproximação entre os saberes e as pessoas, o que reforça a interculturalidade necessária no processo de formação dos professores indígenas e não indígenas.

Compreendemos que é de fundamental importância que as universidades possam formar professores preparados para compreender a realidade do campo ou seja, dos seus espaços de origem, por isso, estes 
professores devem ser oriundos dessa realidade. A partir disso, reconhecemos a importância de se adequar a realidade da formação para que esses futuros educadores possam perceber a especificidade de sua área de atuação. Nesse sentido, reconhecemos que nas licenciaturas Interculturais Indígenas e o PIBID Diversidade cumpre o objetivo de auxiliar nesta formação específica.

Portanto, o PIBID-Diversidade se torna uma proposta interessante levando em conta os benefícios dessa pedagogia e para as comunidades atendidas, pois ela pretende proporcionar uma série de vantagens às escolas das aldeias, propiciando um espaço privilegiado de integração entre as experiências das comunidades com o currículo que parte da realidade e valoriza os saberes locais, estimulando a autonomia dos estudantes.

Buscamos aliar a formação teórica que os discentes já receberam, tanto no PIBID Diversidade como no curso de Licenciatura, buscando desenvolver trabalhos com sequências didáticas e intervenções das escolas indígenas. As propostas procuraram estabelecer uma conexão com as disciplinas das Escolas Indígenas, mas também o trabalho interdisciplinar. Além de conseguir aplicar conteúdos para além dos estabelecidos no currículo ou no livro didático foi possível estimular o desenvolvimento de diferentes recursos audiovisuais, como vídeos e músicas.

Depois da realização dessas atividades consegui participar mais da minha comunidade e também fora da comunidade, as minhas aulas melhoraram muito no estágio supervisionado, acrescentei muitas coisas novas nos meus planejamentos de aula e de diferentes maneiras enriqueci minha prática como professor. Essas experiências só vieram a aprimorar e enriquecer meus conhecimentos [...]. Aprendi ainda a trabalhar com ferramentas audiovisuais aliadas ao ensino como slides, computador, data show entre outros (Relato de um ID do subprojeto de Ciências Humanas- PIBID D/ FAIND/UFGD.

Dentre as diversas atividades desenvolvidas pelo PIBID D, destacamos questões elencadas em cada subprojeto executado nas escolas indígenas, nos quais, o subprojeto de ciências humanas: elencou as discussões sobre as definições do que são os territórios Kaiowá e Guarani; os problemas ocasionados pelo processo histórico de desterritorialização dos Kaiowá e Guarani; estudo dos problemas atuais existentes nas Reservas indígenas descrever a paisagem dos territórios Kaiowá e Guarani e entender a sua organização socioterritorial, relacionando os conflitos envolvendo os Kaiowá e Guarani com a questão das disputas por territórios em MS.

O subprojeto Ciências da Natureza e Matemática, ampliaram as discussões sobre a função articuladora e motivadora das artes no ensino de Ciências da Natureza e Matemática e o diálogo interdisciplinar que o uso da 
arte proporciona em diversos espaços de ensino; promover momentos de estudo e discussão sobre educação escolar indígena, ensino de Ciências; ensino de Matemática; Interdisciplinaridade e Interculturalidade; bem como de temas relevantes nas escolas e comunidades indígenas, tais como problemas ambientais, problemas e cuidados com as aldeias; agroecologia e segurança alimentar; corpo humano, atividades físicas e saúde integrando o ensino de Ciências da Natureza e Matemática; e proporcionar a interação dos bolsistas em atividades realizadas nas escolas indígenas em parceria com projetos de extensão da UFGD e PIBID Ciências da Natureza - (Projeto Bioeducando e oficina "Os Sentidos do corpo humano").

O subprojeto Línguas e Códigos: as principais atividades ações pautaram-se na elaboração de um dicionário temático monolíngue em Kaiowá; Identificar a realidade sociolinguística da comunidade na qual o alternante vive; Trabalhar a contação de histórica como um gênero textual oral aplicável ao ensino de línguas nas escolas indígenas; Elaborar sequências didáticas para o desenvolvimento de Seminários e Debates enquanto gêneros textuais orais a serem praticados nas escolas indígenas guarani e kaiowá; Compreender a importância do desenvolvimento de atividades orais no âmbito escolar na língua materna e na segunda língua e entender os procedimentos de elaboração de relatórios científicos.

Todas essas temáticas foram elencadas em sala de aula a fim de se realizar o estudo teórico e refletir sobre as problemáticas e práticas possíveis que envolvem os conflitos territoriais nas comunidades indígenas.

Aos estudantes, destacamos também, a formação política proporcionada pelo PIBID D, durante a vivência realizada no Ministério de Educação - MEC, em Brasília, onde adquiriram maiores conhecimentos de seus direitos enquanto licenciandos indígenas, e onde puderam perceber como funciona a estrutura do MEC.

Houveram diversos momentos de avaliação, reflexão e planejamento: I e II Seminário Interdisciplinar e Intercultural - ocorrido no primeiro e segundo ano de atividades, respectivamente, reunindo todos os bolsistas do PIBID Diversidade além de convidados externos; I, II, III e IV Seminário Interno de Avaliação e Planejamento. Esses momentos foram imprescindíveis para que 0 PIBID D garantisse a continuidade de suas ações nas escolas parceiras e para divulgar os produtos gerados a partir dos subprojetos.

\section{Resultados e os impactos de projetos anteriores do Pibid Diversidade}

A Licenciatura Intercultural Indígena participou efetivamente do PIBID Diversidade, já a Licenciatura em Educação do Campo, por ser um curso recém-implantado, não pode fazer parte do Programa devido problemas de 
registros institucionais no sistema do MEC. Dentre os resultados obtidos na participação da Licenciatura Indígena destacam-se:

- Produção de vídeos de curta duração para serem utilizados nas escolas como material didático e para participar de festivais nacionais de cinema;

- Oficinas por subprojetos/áreas de como utilizar os vídeos e demais recursos didáticos como instrumento de ensino;

- Reflexões coletivas em eventos internos e estadual sobre a Educação Escolar Indígena;

- Planejamento e aplicação de projetos de ensino nas escolas dos bolsistas participantes;

- Oficina de elaboração de relatórios científicos;

- Apresentação dos resultados de pesquisa dos alunos sobre as situações de uso oral da língua Guarani e da língua Portuguesa dentro e fora da aldeia;

- Definição, produção de textos conversacionais, simulação de diálogos, produção de planos de aula e sequências didáticas para trabalhar o gênero oral Conversação no ensino de português como segunda língua;

- Realização de mesa redonda sobre a ação de extensão Cinema-Educação nas Escolas Indígenas Guarani de Mato Grosso do Sul, com educadores indígenas;

- Contribuição na organização dos espaços da Escola Indígena como a biblioteca escolar;

- Gincanas em diversas áreas do conhecimento escolar nas Escolas Indígenas;

- Jogos recreativos e atividades lúdicas nas escolas;

- Realização do projeto Educando com a horta escolar e projeto Benefícios da atividade físicas e da alimentação saudável;

- Execução de oficinas de formação em matemática para as escolas indígenas;

- Elaboração de diagnóstico dos recursos naturais nas aldeias;

- Publicação de trabalhos completos e apresentações orais nos seguintes eventos: "V Seminário Internacional Fronteiras Étnico-Culturais E Fronteiras Da Exclusão- Inter/Multiculturalidade E Formação De Educadores" UFGD/FCH; IX - ELESI - Encontro de Leitura e Escrita em Sociedades Indígenas, realizado em Porto Seguro -BA; Seminário Fronteiras Étnicas/ANPUH - Campo Grande/MS; II CIAEE (Congresso Ibero-americano de Arqueologia, etnologia e Etno-história); XIV Jornadas Internacionales sobre las Misiones Jesuíticas, em San Inácio - Bolívia; 28ํㅡㄹ Reunião Brasileira de Antropologia - São Paulo/SP; Simpósio Nacional da ANPUH 2013; 
- Projetos de alternância - que permitiram ampliar as discussões realizadas em sala de aula através da aplicabilidade dos conhecimentos em ações/atividades práticas com a comunidade escolar e seu entorno.

- Articulação das Atividades do TEKO ARANDU e PIBID D;

- Oficinas (vídeo, documentários, desenvolvimento de planos de aulas e sequência didática);

- Elaboração e construção de Materiais Didáticos;

- Palestras Projetos de Ensino (IDs, Supervisores, Professores, Mestres Tradicionais, Anciãos, Pais, Mães, crianças e jovens);

- Elaboração de um Dicionário Bilíngue Guarani Kaiowá (2016);

- Materiais didáticos para o ensino de línguas indígena.

\section{Conquistas}

O Projeto PIBID Diversidade foi e é uma oportunidade de aprimoramento para nossos acadêmicos, especialmente se considerarmos as condições de trabalho e de formação dos docentes atuantes nas escolas indígenas. Os subprojetos permitiram aos bolsistas fazerem uma avaliação muito mais profunda das reais necessidades de uma formação de qualidade para os docentes que irão dar continuidade ao trabalho realizado nessas escolas. Isso por si já justificaria a necessidade de continuidade do Programa.

A continuidade do Programa oportunizará aos acadêmicos que estão cursando e que ingressarão nos cursos de licenciatura uma melhor formação para os futuros professores, os quais serão os responsáveis pela permanência dos conhecimentos e saberes tradicionais na escola indígena, valorizando-os e transmitindo também, através da educação escolar, aos futuros indivíduos de suas comunidades, uma educação intercultural, valorizando primeiramente a língua materna e a escrita para que as mesmas permaneçam e sejam valoradas pelas comunidades indígenas de origem.

Ressaltamos que a continuidade é essencial para a concretização da autonomia para a construção de uma proposta político pedagógica diferenciada para as escolas indígenas, bem como a formação de grupos de estudos permanentes e de formação continuada para os professores que atuam nas escolas indígenas.

Durante desenvolvimento das atividades do PIBID D, os bolsistas e suas equipes escolares ampliaram e aprofundaram os estudos de conteúdos e as metodologias aplicadas na educação escolar indígena em suas comunidades; essas discussões contribuíram tanto para a aproximação dos bolsistas às escolas bem como dos demais docentes atuantes nas escolas em questão, 
contribuindo para a melhoria do planejamento que passou a ser coletivo e diferenciado, respeitando os conhecimentos tradicionais e as especificidades de cada comunidade indígena.

Essas ações e discussões também proporcionaram um interesse na formação profissional dos docentes das unidades escolares. Isso foi constatado através do ingresso em cursos e Programas de Pós-graduação (Mestrado na UFGD/Letras), UEMS em Dourados/MS, na UCDB (Universidade Católica Dom Bosco) em Campo Grande/MS e também na UNB (Brasília - PPGLetras) de 05 egressos da Licenciatura Intercultural Indígena Teko Arandu, oriundos das escolas e comunidades indígenas de atuação do PIBID Diversidade/ FAIND/UFGD.

Nesse quarto ano prosseguiu-se com o compartilhamento das atividades do projeto SABERES INDIGENAS NA ESCOLA - MEC/SECADI, junto ao PIBID Diversidade e à Licenciatura Intercultural Indígena, o qual foi muito satisfatório, pois as contribuições desse projeto ressaltaram a necessidade de manter e preservar os saberes tradicionais e tomar conhecimento dos saberes ocidentais para o sucesso da educação escolar indígena.

\section{Desafios}

Dentro do território etnoeducacional do Cone Sul em Mato Grosso do Sul, observamos desde sua implantação, que mesmo com a definição da Constituição de 1988, sobre a necessidade e direito à educação escolar indígena diferenciada, estes requisitos ainda permanecem em fase de fortalecimento.

Embora haja entusiasmo para a concretização dessa realidade, as dificuldades ainda são diversas e dentre elas podemos destacar: a constante presença de Projetos Políticos Pedagógicos organizados sob a ótica da escola não-indígena, fazendo assim que as Secretarias de Educação façam uma análise indiferenciada do processo ensino aprendizagem nas mesmas.

Essa análise indiferenciada acarreta prejuízos em relação aos índices obtidos nas avaliações do MEC para o desempenho dos estudantes, especialmente no ensino fundamental, nas escolas indígenas. Isso porque os mesmos critérios utilizados nas escolas não indígenas para os índices de IDEB, prova Brasil e outras, também são aplicados nas escolas indígenas, o que aponta um descumprimento em relação à educação diferenciada (Grifo Próprio).

Embora a escola indígena seja diferenciada, observamos que muitas vezes ela acaba seguindo os moldes das escolas urbanas e/ou rurais. Os pibidianos do TEKO ARANDU que já atuavam nas escolas indígenas apresentaram resultados significativos em suas aulas quando passaram a compreender qual era o objetivo do PIBID D, e assim puderam incrementar 
suas atividades em sala de aula e também na escola, envolvendo a comunidade escolar em suas ações.

O que percebemos é que nas escolas indígenas há muita dificuldade de separar as necessidades da comunidade das necessidades em sala de aula. As temáticas giram em torno de problemáticas que a comunidade indígena tem enfrentado, estando associadas geralmente às questões ambientais (lixo, queimadas, reflorestamento), a produção de alimentos (hortas escolares e comunitárias) e a valorização do artesanato tradicional (cestaria, casas de reza trançados)... (Relato de um ID do subprojeto de Ciências da Natureza- PIBID D/ FAIND/UFGD).

Nossa proposta não foi somente melhorar a formação dos nossos futuros professores/docentes, mas também dar condições para a melhoria do desenvolvimento do trabalho docente nas escolas e comunidades indígenas, apontando vários meios de se pôr em prática o que é aprendido em sala de aula e que isso pode ser estendido para fora da escola, contribuindo para além da formação docente, principalmente para a formação de cidadãos.

Para os acadêmicos, o PIBID D não só trouxe inovações para a atuação docente, mas também representou uma complementação de renda, contribuindo para a permanência dos estudantes no curso de graduação bem como para melhor qualidade de vida.

Para a universidade. O PIBID D representa uma experiência nova e repleta de desafios a serem vencidos, uma vez que as condições de trabalho e acompanhamento dos acadêmicos indígenas tem suas peculiaridades por ocorrer em alternância. Entretanto, foi possível demonstrar que é possível desenvolver ações que resultem em benefício da formação docente, bem como da melhoria da qualidade do ensino diferenciado nas escolas indígenas, mesmo que os subprojetos sejam alternantes.

A UFGD também teve como benefícios através do PIBID D ampliar o diálogo com as Secretarias Estaduais e Municipais e com a realidade das escolas indígenas do Cone Sul de MS, sendo possível identificar as fragilidades nos processos de ensino/aprendizagem que essas escolas enfrentam. Para a Licenciatura Intercultural Indígena, o PIBID D tem proporcionou ricos momentos de discussão sobre a educação escolar indígena e oportunizado o desenvolvimento de ações nas escolas indígenas localizadas na região Sul de MS, contribuindo para o crescimento individual e coletivo do corpo docente que atua nesse curso e de seus acadêmicos.

Considerando a necessidade de refletir as práticas metodológicas aplicadas nos cursos de licenciatura, o PIBID D tem contribuído para maior reflexão na escolha dos conteúdos, nas metodologias aplicadas e nos 
processos avaliativos associando-os aos contextos e realidades locais; a escolha das ações que serão executadas através do PIBID D tem sido um exercício contínuo de pensar diferentes temáticas através da interdisciplinaridade e interculturalidade.

Mesmo diante dos desafios, tanto nas necessidades apresentadas pelas unidades escolares bem como pelos docentes que atuam nesses espaços (falta de materiais didático pedagógicos, infraestrutura dos prédios, recursos para aulas diferenciadas, difícil acesso principalmente em períodos de chuva), as ações do PIBID D possibilitaram superar dificuldades de diálogo entre Educação Básica e Ensino Superior, principalmente através da união de diferentes áreas de formação nas ações desenvolvidas.

\section{REFERÊNCIAS}

ASSIS, Alessandra Santos de. O PIBID como política pública para a formação docente. Revista Thema. Disponível em:

$<$ <ttp://revistathema.ifsul.edu.br/index.php/thema/article/viewFile/391/192>

DE PAULA, L. R. e VIANNA, F. de L. B. Mapeando Políticas Públicas para Povos Indígenas - Guia de pesquisa de ações federais. Rio de Janeiro: Contra Capa Livraria; LACED/Museu Nacional/UFRJ, 2011.

FUNDAÇÃO CARLOS CHAGAS. Um estudo avaliativo do Programa Institucional de Bolsa de Iniciação à Docência (Pibid). Bernardete A. Gatti; Marli E. D. A. André; Nelson A. S. Gimenes; Laurizete Ferragut,(pesquisadores) - São Paulo: FCC/SEP, 2014.

ROSSATO. V. L. O Modo de ser Guarani e Kaiowá em Mato Grosso do Sul. IN: VINHA; M., FERREIRA, M. B. R.,MOURA, N.dos S. P., ABREU, S., CAMARGO,V. R. T., ROSSATO, V. L. Educação escolar Guarani e Kaiowá: Território Etnoeducacional Cone Sul. Dourados: FUNDECT/UFGD, 2015. p. 07-11.

SILVA, S. M. da; NUNES, C. P. O Pibid como política pública de formação de professores. Educação em Debate, Fortaleza, ano 38 - ำ72, 2016, p.89-103. Disponível em:

<http://www.periodicosfaced.ufc.br/index.php/educacaoemdebate/article/view/62/26> 